\title{
Effects of Electroconvulsive Shock and Puromycin on Operant Responding in Goldfish'
}

\author{
MARI S. GOLUB ${ }^{2}$, MARY LOU CHEAL AND ROGER E. DAVIS \\ Mental Health Research Institute and Department of Psychology, University of Michigan, \\ Ann Arbor, Michigan 48104, U.S.A.
}

(Received 3 July 1971)

\begin{abstract}
Golub, M. S., M. L. ChEAL AND R. E. DAVIS. Effects of electroconvulsive shock and puromycin on operant responding in goldfish. PHYsiol. BeHAv. 8 (4) 573-578, 1972.-Goldfish were conditioned to strike an operandum for food reward on a variable interval schedule. Well-established patterns of operant responding were disrupted for up to several days when the fish were convulsed by a $1 \mathrm{sec}$ transcranial shock immediately following a regular daily session. No lasting interference was seen when fish were shocked $19.5 \mathrm{hr}$ postsession. The results suggest that the convulsive shock has aversive consequences which can be conditioned to stimuli associated with the training environment in a single presentation. Intracranial administration of $170 \mu \mathrm{g}$ of puromycin immediately following a session did not disrupt responding.
\end{abstract}

Electroconvulsive shock Puromycin Operant conditioning Goldfish

RETENTION of shock avoidance learning in the goldfish can be impaired by administering electroconvulsive shock (ECS) or intracranial puromycin within a limited period of time after avoidance training $[4,5,6]$. The time-dependence of the amnesic effect of agents administered following learning suggests that the apparent memory loss is a result of a disruption of storage processes [18].

A series of experiments with goldfish has shown, however, that the amnesia produced by ECS and puromycin depends not only on the time elapsed since the learning experience, but also on the stimulus environment of the animal just prior to treatment $[4,7,11]$. In fact, retention deficits can be produced long after memory storage is presumably complete if the appropriate environmental conditions are instituted before treatment. Environment-dependent amnesias have also been reported in rats and mice $[13,20,22,23,24,25]$ although some investigators were not able to confirm these findings $[12,25]$.

The demonstration of environment-dependence suggests that ECS- and puromycin-produced retention deficits are not exclusively a result of the disruption of memory formation. Further, this finding emphasizes the importance of a more complete description of the behavioral effects of amnesic agents in situations where recency of learning is not the major consideration.

In the following experiments, we administered ECS or puromycin between sessions of operant responding. The operant behavior was maintained on an intermittent schedule of food reinforcement. The purpose was to determine whether performance of a well-established pattern of responding would be disrupted by a single presentation of these agents, and whether the interference could be decreased by delaying the time at which the agent is applied following the session as in a conventional retrograde amnesia paradigm.

\section{METHOD}

Goldfish (Carassius auratus) weighing 8.5-12.5 g were maintained in continuously filtered, $19-20^{\circ} \mathrm{C}$ water in individual 9.51 glass aquaria during the experiment. These home tanks were stored in a continuously illuminated room. In addition to food reinforcement obtained during experimental sessions, each fish received supplemental feeding of brine shrimp in its home tank. The fish were obtained from Ozark Fisheries, Stoutland, Missouri, during the period of September-November 1970 , for the ECS experiment, and during the following three months for the puromycin experiment.

\section{Apparatus}

The experimental tank was a 9.51 glass aquarium. A plastic grid formed a false floor which limited the fish's activity to the upper half of the tank. A water level of $9 \mathrm{~cm}$ above the grid floor was maintained by a constant flow of dechlorinated $20^{\circ} \mathrm{C}$ tap water. The experimental tank was

\footnotetext{
${ }^{1}$ Supported by PHS Research Development Award K2-MH-22183 to R.E.D. from the National Institutes of Mental Health. Reprints can be obtained from R. E. Davis.

2Present address: Behavioral Pharmacology Laboratories, Boston University Medical School, 80 E. Concord, Boston, Massachusetts 02118 U.S.A.
} 
contained in a top-opening ice chest and lit from above by a $40 \mathrm{~W}$ bulb. The tip of the operandum, a Gibbs inertial switch [10] was suspended near the center of the tank about $3 \mathrm{~cm}$ below the water level. A feedback lamp (Sylvania 120 BSP) and a feeder which dispensed reinforcement of 3-4 brine shrimp [8] were positioned near the operandum above the water surface. Operandum, feeder and feedback lamp were clamped firmly to aluminum rods mounted over the opening of the ice chest.

A BRS-Foringer 200 Series Digibit system controlled events and data collection. Responses and reinforcements were registered on a cumulative recorder. Interresponse times (IRTs) exceeding $400 \mathrm{msec}$ were registered to the nearest $200 \mathrm{msec}$ on paper tape and assembled into frequency distributions with a PDP-8 computer. Statistical analyses were carried out with an IBM 360 computer.

The ECS consisted of a $5 \mathrm{~mA}, 1 \mathrm{sec}$ pulse of $60 \mathrm{~Hz}$ alternating current. The shock was obtained with a constant current power amplifier in conjunction with an oscillator. ECS was administered between two electrodes which were pressed dorsolaterally on the cranium just posterior to the eyes. Fish were held in one hand while the electrodes were applied with the other.

Puromycin was injected with a $100 \mu 1$ Hamilton syringe and a 30 gauge needle. The drug was dissolved in $0.15 \mathrm{M}$ sodium chloride and administered in a single $10 \mu$ injection into the cranial cavity over the midbrain. The needle penetrated the roof of the cranium approximately $2 \mathrm{~mm}$, at a point on the median surture in line with the posterior margin of the eyes.

\section{Procedure}

Fish were transferred by hand from home tanks to a smaller transport tank and carried to the experimental room for each $30 \mathrm{~min}$ session. Responding to the operandum was developed on a continuous reinforcement schedule. A variable interval (VI) schedule was then introduced and gradually increased over several sessions to a terminal value of VI $3 \mathrm{~min}$. About $60 \%$ of fish were rejected as possible subjects by this stage of training. Fish were selected which showed stable, moderate to high rates of responding.

Fish were then assigned to one of two training schedules. Schedule A fish were trained daily except Sunday and Schedule B fish were trained every second or third day. This stage of training continued over an additional three to six weeks. It was terminated when the individual showed closely similar patterns of responding in three successive sessions. An additional $20 \%$ of fish started in training were discarded during this stage. No attempt was made to match the performance of fish within a group or in different groups. Fish were assigned in rotation to each group in each experiment.

ECS experiment. Three Schedule A and three Schedule B fish were given ECS immediately following the final baseline session (Groups A-O and B-O). Three additional fish on each schedule received ECS $19.5 \mathrm{hr}$ after the final baseline session (Groups A-20 and B-20) at which time the fish were momentarily lifted from the home tank in the storage room. Following the ECS treatment, the twelve fish received three additional operant sessions. The sessions occurred at $24 \mathrm{hr}$ intervals for A-O and A-20 fish and at $48 \mathrm{hr}$ intervals for B-O and B-20 fish. Thus the interval between ECS and the next session was $23.5 \mathrm{hr}$ for group A-O, $4 \mathrm{hr}$ for group A-20, $47.5 \mathrm{hr}$ for B-O, and $28 \mathrm{hr}$ for B-20.

Puromycin experiment. An intracranial injection of $170 \mu \mathrm{g}$ of puromycin was given to four fish immediately following the final baseline session, and to an additional four fish $19.5 \mathrm{hr}$ following the session. Another four fish received an intracranial injection of saline without puromycin immediately postsession. Each fish was given three more daily sessions starting seven days after the final baseline session.

\section{RESULTS}

Stable response rates recorded in the three sessions just prior to ECS or puromycin treatment ranged from 6 to 16 responses per min. Fish responded most frequently by striking or tapping the operandum with their lips or snout. Some individuals occasionally hit with the side of their head. The IRT frequency distributions typically showed two peaks (Fig. 1). One peak was comprised of IRTs of about 1 sec. These short IRTs represented approximately $20 \%$ of the responses in a session and they mostly occurred during visits to the reinforcement area. The second peak was of IRTs of about $5-10 \mathrm{sec}$, for different individuals, and it represented the most frequent interval between visits to the reinforcement area. This interval we refer to as the pace. About $70 \%$ of the responses were distributed around this peak. The remaining were spaced at intervals greater than $15 \mathrm{sec}$. These long IRTs were breaks or pauses in the fish's pace of responding. For data analysis, the three classes of IRTs were specified as follows. In the ECS experiment: short, IRT $<1.5 \mathrm{sec}$; pace, $1.5 \leq$ IRT $<15 \mathrm{sec}$; long, IRT $\geq 15 \mathrm{sec}$. In the puromycin experiment, the short IRT bin was increased to IRTs $<2.0$ sec and the pace IRT bin was correspondingly reduced.

\section{ECS effects}

The number of responses in a session and the proportion of short, pace and long IR'Ts were used as independent measures of performance. The data in the three baseline sessions were combined for each group to obtain a single estimate of the mean for each of the four measures (Table 1). The difference between the baseline values and the group means in the three successive posttreatment sessions was assessed with a $t$-test for paired means (degrees of freedom $=2$ ).

The paired means analysis reveals that total responses per session dropped significantly in the first posttreatment session for groups A-O, B-O and A-20 but not B-20. The cumulative records in Fig. 1 illustrate the decreases shown by an A-O and an A-20 fish. Groups A-O and B-O also showed significantly fewer responses in the second posttreatment session. In the third session, all the groups responded at their pre-ECS levels.

Significant changes in proportions of IRTs of different classes occurred. The greatest effect was in fish which received ECS immediately postsession. In the first and second posttreatment session, group A-O showed an increase mean proportion of long IRTs (see fish A-17, Fig. 1) while B-O showed a reduced proportion of short IRTs. The IRT distributions in the third session were not significantly different from baseline for groups A-O, B-O and A-20. Group A-20 showed a small drop in short IRTs in the first post-ECS session but otherwise the group average IRT distribution did not differ significantly from the baseline. One fish in the group showed conspicuous changes. In addition to the drop in short IRTs, compared to baseline, the proportion of pace IRTs decreased $40 \%$ and long IRTs increased a corresponding amount. The most stable IRT distributions were those of B-20. A very small but significant increase in the proportion 


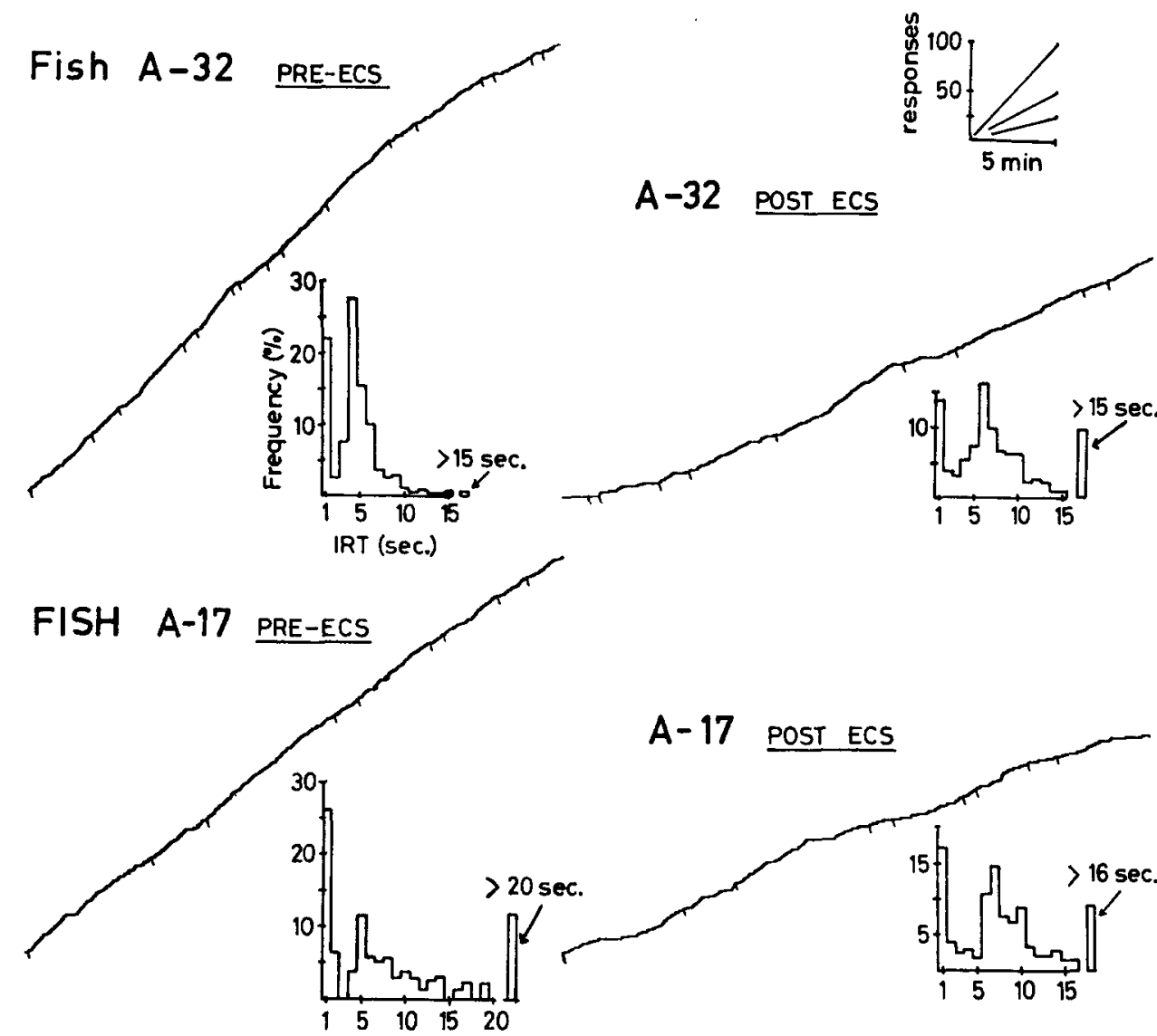

FIG. 1. Cumulative records and IRT distributions of 2 fish before and after an immediate postsession ECS. Fish A-17 was in Group A-0, and A-32 was in Group A-20. Reinforced responses are indicated by the downward deflections of the cumulative record trace.

of long IRTs was seen in the first and third post-ECS session. No other significant changes occurred.

The results of an analysis of variance of a $4 \times 2$ design, groups $\mathrm{X}$ pre- and posttreatment sessions, are summarized in Table 2. The total responses per session and the proportion of long IRTs in the first and second post-ECS sessions revealed a significant treatment effect. The change in the proportion of short IRTs in the second post-ECS session is significant. The pace IRTs showed no significant treatment effects. The differences between the groups are nonsignificant except for the mean proportion of pace IRTs in the second post-ECS session. Since the subjects were few and unmatched for performance prior to treatment, the analysis of variance is less appropriate for assessing differences between groups than the paired means test in Table 1 .

\section{Puromycin Effects}

Intracranial puromycin had no significant effects on the patterns of responding (Table 3 ) as analysed by the $t$-test of paired means. Few of the values of $t$ are even close to the $0.05 \%$ level of significance $(t=2.92, d f=2)$. The saline group showed a small drop in the proportion of long IRTs in the third posttreatment session. The possible relation between this shift and the intracranial injection of saline is obscure to us.
Analysis of variance (Table 4) generally confirms the result of the paired means test. The only significant treatment effect was in the proportion of pace IRTs in the first posttreatment session. The data for that session (Table 3) suggests a slight flattening of the IRT distribution compared to baseline.

\section{DISCUSSION}

These results indicate that a postsession ECS, but not intracranial puromycin, can disrupt subsequent performance of a well established operant task. Moreover, the ECS effect varies as a function of the time elapsed between the end of a session and administration of ECS. As the immediate and delayed ECS treatments were administered in different rooms the external stimulus conditions just prior to the treatment may be an important variable. An immediate postsession ECS results in interference in the next session a day or two days later and for subsequent sessions up to four days following the ECS. ECS administered $19.5 \mathrm{hr}$ postsession, however, had only a short-term effect. Some interference was seen when the next session started $4 \mathrm{hr}$ after the ECS (Group A-20) but not when it was delayed until the next day (Group B-20), and performance in subsequent sessions was unimpaired. It is noteworthy that even during these severely disrupted sessions, fish approached and struck the operandum over 100 times and obtained the reinforcements usually earned during the session. 
TABLE 1

ECS Experiment: The Mean Total Responses Per Session and the Mean Proportions of Short, Pace and Long IRTs in the Three Sessions Preceeding and Following Administration OF ECS

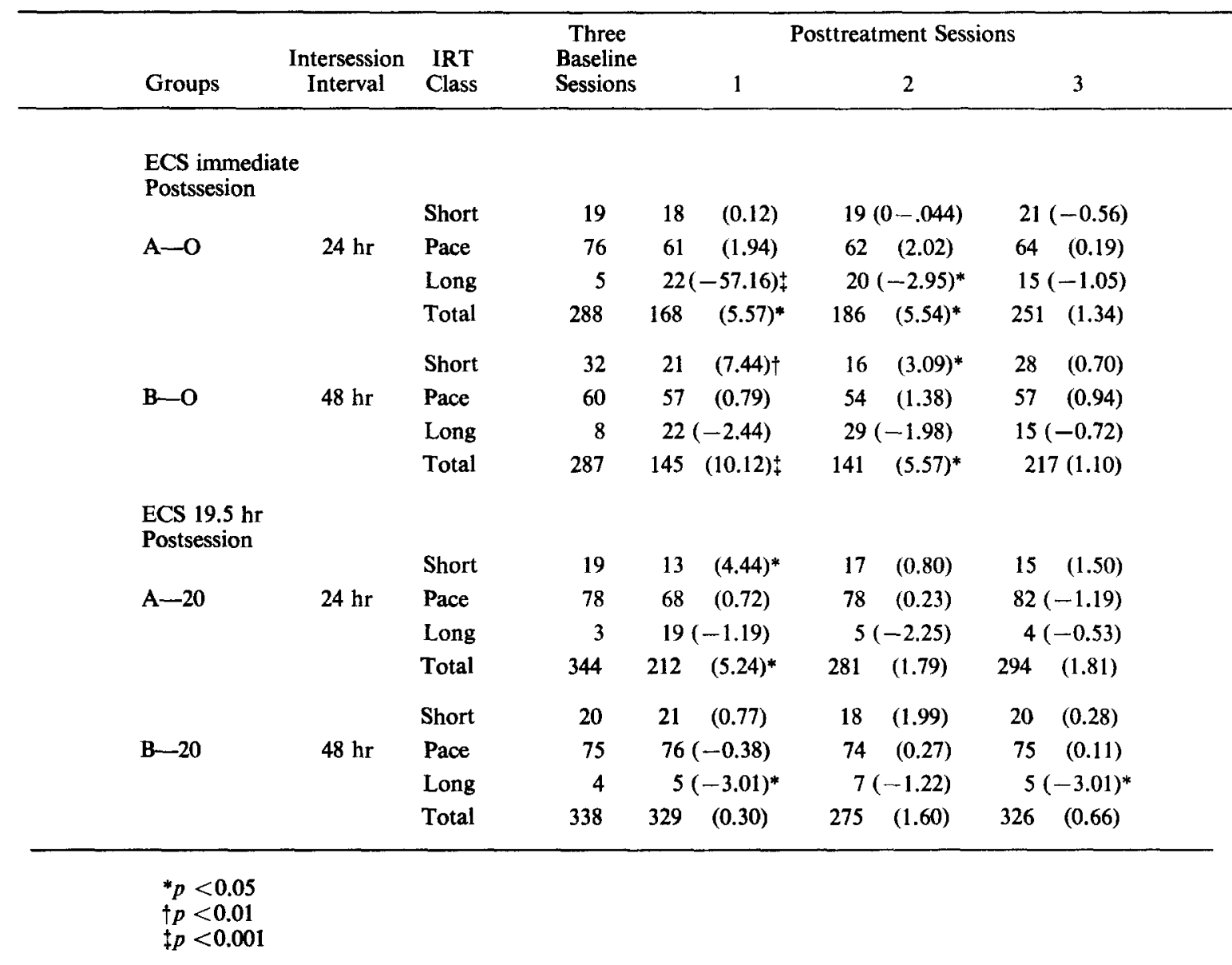

TABLE 2

ECS Experiment: Values of F-Tests Contrasting the Combined Baseline Sessions and the Three Posttreatment Sessions

\begin{tabular}{|c|c|c|c|c|c|c|c|c|c|c|c|c|c|}
\hline \multirow{3}{*}{ Source } & \multirow{3}{*}{$\begin{array}{l}\text { Degrees } \\
\text { Freedom }\end{array}$} & \multirow{2}{*}{\multicolumn{3}{|c|}{$\begin{array}{l}\text { Short } \\
\text { session }\end{array}$}} & \multicolumn{6}{|c|}{ IRT Class } & \multirow{2}{*}{\multicolumn{3}{|c|}{$\begin{array}{l}\text { Total } \\
\text { session }\end{array}$}} \\
\hline & & & & & & $\begin{array}{l}\text { Pace } \\
\text { sessio }\end{array}$ & & & $\begin{array}{l}\text { Long } \\
\text { session }\end{array}$ & & & & \\
\hline & & 1 & 2 & 3 & 1 & 2 & 3 & 1 & 2 & 3 & 1 & 2 & 3 \\
\hline Groups & 3,8 & 1.4 & 0.6 & 2.0 & 3.0 & 4.9 & 3.1 & 1.0 & 2.0 & 0.6 & 1.7 & 1.5 & 0.6 \\
\hline Treatment & 1,8 & 4.8 & 10.4 & 0.6 & 3.0 & 2.9 & 0.7 & $11.0^{*}$ & $11.9 \dagger$ & 1.8 & $73.9+$ & $36.8 \dagger$ & 4.8 \\
\hline $\mathbf{G} \times \mathbf{T}$ & 3,8 & 1.3 & 5.6 & 0.5 & 0.7 & 1.9 & 0.9 & 1.1 & 2.2 & 0.4 & 7.0 & 1.6 & 0.4 \\
\hline
\end{tabular}

$* p<0.05$

$\dagger p<0.01$

The ECS-produced interference consisted most conspicuously of reduction in the overall rate of responding, or increased pauses in responding during the $30 \mathrm{~min}$ session. Long pauses punctuated intervals of normal appearing patterns of responding. There was nothing to suggest that the fish had forgotten certain elements of the well established task. But we cannot rule out the possibility that the interference represents a memory loss. Memory activated during a session might be vulnerable to interference by an immediate postsession ECS [7, 13, 22]. 
TABLE 3

Puromycin Experiment: The Mean Total Responses Per Session and the Mean Proportion of Short, Pace and long IRTs in the Three Sessions Preceeding and Following Administration of Puromycin

\begin{tabular}{|c|c|c|c|c|c|c|c|c|c|}
\hline \multirow[t]{2}{*}{ Groups } & \multirow[t]{2}{*}{$\begin{array}{l}\text { Intersession } \\
\text { Interval }\end{array}$} & \multirow{2}{*}{$\begin{array}{l}\begin{array}{l}\text { IRT } \\
\text { Class }\end{array} \\
\text { Short }\end{array}$} & \multirow{2}{*}{$\begin{array}{c}\begin{array}{c}\text { Three } \\
\text { Baseline } \\
\text { Sessions }\end{array} \\
12\end{array}$} & \multicolumn{6}{|c|}{ Posttreatment Sessions } \\
\hline & & & & 12 & $(0.12)$ & 12 & $(0.06)$ & 9 & $(1.72)$ \\
\hline puromycin & 7 days & Pace & 83 & 78 & $(0.72)$ & 82 & $(0.29)$ & 86 & $(2.62)$ \\
\hline \multirow[t]{3}{*}{ immediate } & & Long & 6 & 10( & $-0.87)$ & 6 & $(0.00)$ & 5 & $(0.49)$ \\
\hline & & Total & 288 & 248 & $(1.14)$ & \multicolumn{2}{|c|}{$289(-0.10)$} & 289 & $(0.11)$ \\
\hline & & Short & 22 & \multicolumn{2}{|c|}{$28(-1.80)$} & \multicolumn{2}{|c|}{$40(-1.73)$} & 28 & $(1.13)$ \\
\hline puromycin & 7 days & Pace & 70 & 49 & $(1.76)$ & 65 & (1.38) & 48 & $(1.64)$ \\
\hline \multirow[t]{3}{*}{$19.5 \mathrm{hr}$ delay } & & Long & 7 & 9 & $(0.50)$ & 24 & $(1.00)$ & 8 & $(0.24)$ \\
\hline & & Total & 267 & 257 & $(0.24)$ & 275 & $(0.40)$ & 277 & $(0.29)$ \\
\hline & & Short & 27 & \multicolumn{2}{|c|}{$30(-0.48)$} & 30 & $(0.85)$ & 22 & $(0.74)$ \\
\hline saline & 7 days & Pace & 64 & 59 & $(1.05)$ & 66 & $(0.66)$ & 56 & $(0.67)$ \\
\hline \multirow[t]{2}{*}{ immediate } & & Long & 8 & 14 & $(0.86)$ & 19 & $(0.78)$ & 5 & $(4.02)^{*}$ \\
\hline & & Total & 287 & 274 & $(0.50)$ & 317 & $(2.32)$ & 305 & $(1.14)$ \\
\hline
\end{tabular}

${ }^{*} p<0.05$

TABLE 4

Puromycin Experiment: Values of F-Tests Contrasting the Combined Baseline Sessions and the Three Postrreatment Sessions

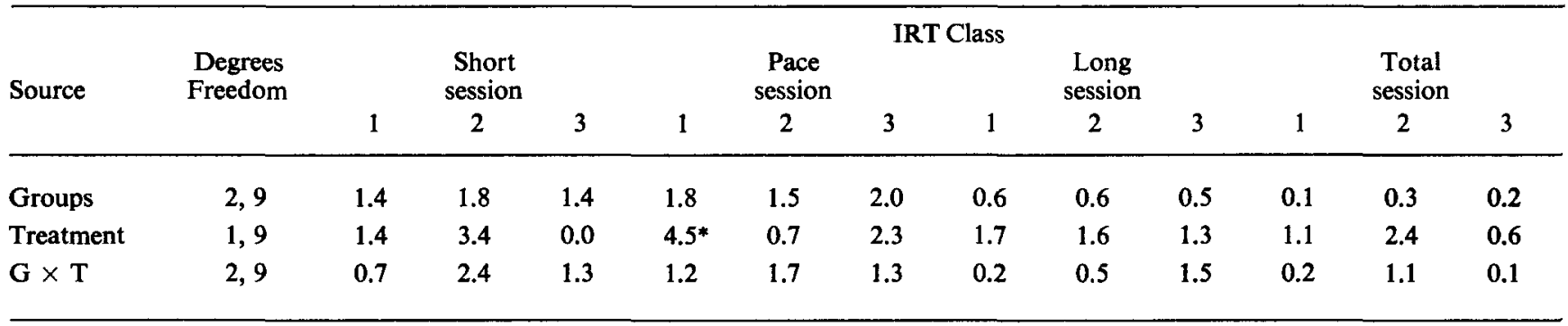

${ }^{*} p<0.05$

We propose, however, that the present results show two effects of ECS neither of which entails a loss of memory. The short-term effect of the delayed ECS is attributed to an anterograde debilitation which occurs during the postconvulsive recovery period and is presumably not correlated with the time elapsed since the previous session. The longterm effect produced by the immediate ECS can be interpreted as indicating that shock treatment has aversive consequences which can be conditioned to stimuli associated with the training environment in a single presentation. Experiments in laboratory rodents have shown that multiple ECS treatments can produce punishment and negative reinforcement $[3,14,16]$. Lewis and Maher [17] postulate that ECS can also act as an unconditioned stimulus in Pavlovian conditioning. Aversive effects of a single ECS, as typically used in experiments on the amnestic effects of ECS in the laboratory rat have been described [21]. Stimulus effects of amnestic agents could be responsible for environment-dependent amnesia in goldfish [7]. The present demonstration that a single ECS treatment has behavioral effects which can be attributed to the stimulus properties of the treatment supports this possibility. Recent unreported experiments suggest that the operant responding can also be disrupted by administering the shock across the fish's tail immediately postsession. The behavioral effects of ECS and tail shock, however, may not be identical. For instance, a tail shock does not duplicate the amnesic effect of ECS in goldfish [7].

ECS has been administered to rodents in conjunction with measures of steady-state performance $[1,19,26,27,28]$. However the individual animal's performance of schedule maintained responding before and after a single postsession ECS was not compared. While our findings do not relate directly to amnesias produced in other animals, or to the behavioral effects of other amnesic agents, they do suggest that 
the stimulus properties of amnesic agents can be assessed directly if sensitive measures of individual behavior are employed.

Intracranial puromycin did not disrupt the patterning of responding. Effects of puromycin were examined after seven days, or an interval longer than one or two days, on the basis of previous experience with this drug. Puromycinproduced amnesia in goldfish develops over a period of several days $[5,11]$, not within minutes or hours as does amnesia induced by ECS [7, 9]. Our aim was to detect lasting interference effects of the drug and not any temporary anterograde effects which might result from the injection. The dose of puromycin was the largest that had routinely been used in amnesia experiments without some signs of impaired performance of avoidance responding. Some temporary, possibly mild disablement was anticipated. An injection of $170 \mu \mathrm{g}$ of puromycin results in an $80 \%$ suppression of brain protein synthesis for up to 10-12 hr [2]. But observations made following this experiment showed that the puromycin also has little or no immediate effect on responding. For example, fish injected just prior to or in the middle of a session exhibited no consistent disruption of behavior in the session. These results suggest that performance of the operant and consummatory responses is not dependent on the central neverous system processes that are impaired by intracranial puromycin.

\section{REFERENCES}

1. Adams, H. E., L. J. Peacock and D. D. Hamrick. ECS and onetrial learning: Retrograde amnesia or disinhibition? Physiol. Behav. 2: 435-437, 1970.

2. Brink, J. J., R. E. Davis and B. W. Agranoff. Effects of puromycin, acetoxycycloheximide and actinomycin $D$ on protein synthesis in goldfish brain. J. Neurochem. 13: 889-896, 1966.

3. Coons, E. E. and N. E. Miller. Conflict versus consolidation of memory traces to explain "retrograde amnesia" produced by ECS. J. comp. physiol. Psychol. 53: 524-553, 1960.

4. Davis, R. E. Environmental control of memory fixation in goldfish. J. comp. physiol. Psychol. 65: 72-78, 1968.

5. Davis, R. E. and B. W. Agranoff. Stages of memory formation in goldfish: Evidence for an environmental trigger. Proc. natl Acad. Sci. 55: 555-559, 1966.

6. Davis, R. E., P. B. Bright and B. W. Agranoff. Effect of ECS and puromycin on memory in fish. J. comp. physiol. Psychol. 60: 162-166, 1965.

7. Davis, R. E. and M. S. Hirtzel. Environmental control of ECSproduced retrograde amnesia in goldfish. Physiol. Behav. 5: 1089-1092, 1970.

8. Davis, R. E. and M. S. Hirtzel. An inexpensive brine shrimp dispenser for fish. Behav. Res. Meth. Instr. 2: 262-263, 1970.

9. Davis, R. E. and P. A. Holmes. ECS-produced retrograde amnesia of conditioned inhibition of respiration in cataleptic goldfish. Physiol. Behav. 7: 11-14, 1971.

10. Davis, R. E. and R. B. Kenyon. Registration of operant responses in fish. Behav. Res. Meth. Instr. 3: 19, 1970.

11. Davis, R. E. and P. D. Klinger. Environmental control of amnesic effects of various agents in goldfish. Physiol. Behav. 4: 269-271, 1969.

12. Dawson, R. G. and J. L. McGaugh. Electroconvulsive shock effects on a reactivated memory trace: further examination. Science 166: 525-527, 1969.

13. Howard, R. L. and D. R. Meyer. Motivational control of retrograde amnesia in rats: A replication and extension. J. comp. physiol. Psychol. 74: 37-40, 1970.

14. Hudspeth, W. J., J. L. McGaugh and C. W. Thompson. Aversive and amnesic effects of electroconvulsive shock. J. comp. physiol. Psychol. 57: 61-67, 1964.
15. Jamieson, J. L. and D. J. Albert. Amnesia from ECS: the effects of pairing ECS and footshock. Psychonom. Sci. 18: 14 $16,1970$.

16. Kesner, R. P., W. E. Gibson and M. J. LeClair. ECS as a punishing stimulus: dependency on route of administration. Physiol. Behav. 5: 683-686, 1970.

17. Lewis, D. J. and B. A. Maher. Neural consolidation and electroconvulsive shock. Psychol. Rev. 72: 225-239, 1965.

18. McGaugh, J. L. Time-dependent processes in memory storage. Science 153: 1351-1358, 1966.

19. McGaugh, J. L. and B. Longacre. Effects of electroconvulsive shock on performance of a well-learned avoidance response: contribution of the convulsion. Communs Behav. Biol. 4: $177-181,1969$.

20. Miller, R. R., J. R. Misanin and D. J. Lewis. Amnesia as a function of events during the learning-ECS interval. J. comp. physiol. Psychol. 67: 145-148, 1969.

21. Misanin, J. R. Role of fear in the facilitation and inhibitory effects of electroconvulsive shock. J. comp. physiol. Psychol. 61: $411-415,1966$.

22. Misanin, J. R., R. R. Miller and D. J. Lewis. Retrograde amnesia produced by electroconvulsive shock after reactivation of a consolidated memory trace. Science 160: 554-555, 1968.

23. Potts, W. J. The effect of different environments prior to electroconvulsive shock on the gradient of retrograde amnesia. Physiol. Behav. 7: 161-164, 1971.

24. Robustelli, F., A. Geller and M. E. Jarvik. Combined action of two amnesic treatments. Communs Behav. Biol. 4: 221$229,1969$.

25. Schneider, A. M. and W. Sherman. Amnesia: A function of the temporal relation of footshock to electroconvulsive shock. Science 159: 219-221, 1968.

26. Schneider, A. M., A. Malter and C. Advokat. Pretreatment effects of a single ECS and footshock plus ECS on step-down latencies of trained and untrained rats. J. comp. physiol. Psychol. 68: 627-630, 1969.

27. Sprott, R. L. and M. B. Waller. The effects of electroconvulsive shock on the action of reinforcing stimulus. J. exp. Analysis Behav. 9: 663-669, 1966.

28. Young, A. G. and A. D. Day. ECS effects following continuous and partial reinforcement training. Psychonom. Sci. 21: 131132, 1970. 